\title{
Irish Division: Annual Meeting, 1981
}

The Annual Meeting of the Irish Division was held at St Patrick's Hospital, Dublin, on 30 October 1981. The theme of the clinical section of the meeting was: 'The Psychotherapies-What of the Future?' There was an exceptionally large attendance at this meeting, no doubt reflecting the interest in psychotherapy amongst Irish psychiatrists. Three excellent papers were presented. The first-'What is a psychotherapist?' delivered by the President of the College, Professor Kenneth Rawnsley, discussed the suggested setting up in the United Kingdom of a Register of Psychotherapists, and outlined the various conditions that would be required if such a register were established.

The second paper, by Dr John Cobb, entitled 'Depth, structure and direction of psychotherapy' concentrated on the interphase between behavioural and dynamic orientated psychotherapy. Dr Cobb emphasized the importance of the cognitive approach to psychotherapy and predicted a growing interest in this area over the next decade.

The third paper, delivered by Dr Sidney Bloch, on 'The group approach' compared and contrasted three different models of group psychotherapy. Dr Bloch drew attention to the similarities which exist between the behavioural and dynamic approaches.
All three papers provoked lively discussion and underlined the genuine interest and concern by Irish psychiatrists that psychotherapy be given a higher profile in postgraduate training in Ireland than exists at present. A succinct summary of the papers was presented by Professor Noel Walsh.

The Business Meeting, chaired by Professor T. Lynch, reported on the recent meeting with Department of Health officials. Professor T. Fahy outlined a document he had prepared on conditions in Irish psychiatric hospitals and requested that a consultative body be set up as soon as possible, to liaise with the Department of Health on this urgent issue.

The Chairman gave further details of the combined meeting of the Irish Division and the American Psychiatric Association Post-Convention Symposium, to be held in Dublin in May 1982.

The members expressed their appreciation to Professor $\mathbf{P}$. J. Meehan, Medical Director, St Patrick's Hospital and the hospital staff for hosting this very successful meeting.

David Shanley Honorary Secretary

\section{News Items}

\section{Dr Adam Limentani}

Dr Adam Limentani, Fellow of the British PsychoAnalytical Society, has recently been made President of the International Psycho-Analytical Society.

\section{Association for Psychoanalytic Psychotherapy in the NHS}

The Association for Psychoanalytic Psychotherapy in the NHS has been formed. The aims of the Association are to promote and develop understanding of psychoanalytic psychotherapy and to increase its availability in the NHS.
Dr John Steiner is Chairman, Dr Michael Michalacopoulos, Secretary and Dr Sheilagh Davies, Treasurer. Those interested should contact the Secretary at Queen Mary's Hospital, Roehampton, London SW 15.

\section{Management of Addiction}

The Association of Independent Doctors in Addiction (AIDA) has been formed for doctors both in the NHS and private practice who are interested or involved in the management of drug addiction outside clinics.

Any interested doctors should write, enclosing an s.a.e., to Dr Ann Dally, 13 Devonshire Place, London W IN IPB. 